\title{
Особенности селективного легирования марганцем GaAs структур
}

\author{
() И.Л. Калентьева 1 ฯ, О.В. Вихрова ${ }^{1}$, Ю.А. Данилов ${ }^{1}$, Б.Н. Звонков ${ }^{1}$, А.В. Кудрин ${ }^{1}$, М.В. Дорохин ${ }^{1}$, \\ Д.А. Павлов ${ }^{1}$, И.Н. Антонов ${ }^{1}$, М.Н. Дроздов ${ }^{2}$, Ю.В. Усов ${ }^{1}$ \\ ${ }^{1}$ Нижегородский государственный университет им. Н.И. Лобачевского, \\ 603950 Нижний Новгород, Россия \\ ${ }^{2}$ Институт фризики микроструктур Российской академии наук, \\ 603950 Нижний Новгород, Россия \\ ฯ E-mail: istery@rambler.ru
}

(Получена 27 апреля 2017 г. Принята к печати 12 мая 2017 г.)

Исследовано влияние технологических параметров на селективное легирование марганцем арсенидгаллиевых гетероструктур, изготавливаемых сочетанием методов МОС-гидридной эпитаксии и импульсного лазерного нанесения. В качестве этих параметров использованы: содержание примеси в $\delta$-слое марганца и температура формирования структуры. Установлено, что при температуре выращивания $\sim 400^{\circ} \mathrm{C}$ и содержании примеси не более $0.2-0.3$ монослоя изготовленные структуры демонстрируют наибольшую электрическую активность и обладают ферромагнитными свойствами. Изучение выращенных структур методами спектроскопии отражения, высокоразрешающей просвечивающей электронной микроскопии и вторичной ионной масс-спектрометрии показало, что применение указанных выше условий при импульсном лазерном нанесении позволяет получать арсенид-галлиевые структуры, которые имеют хорошее кристаллическое качество, а марганец в таких структурах сосредоточен в тонком (7-8 нм) слое без существенного диффузионного размытия и сегрегации.

DOI: 10.21883/FTP.2017.11.45092.06

\section{1. Введение}

Селективное легирование магнитной примесью ( $3 d$ переходными металлами и Мn в частности) является перспективным способом создания ферромагнитной области в полупроводниковых гетеронаноструктурах для приборов спиновой электроники. Благодаря этому приему гетероструктуры сохраняют высокое кристаллическое и оптическое качество и демонстрируют характеристики, обусловленные присутствием спинполяризованных носителей заряда. Известно, что при формировании $\delta$-слоя $\mathrm{Mn}$ в структурах на основе $\mathrm{GaAs}$ реализуется ферромагнитное упорядочение $[1,2]$. $\delta$-легированный слой - это область эпитаксиальной структуры, в которой профиль примеси имеет вид $\delta$-функции, т.е. резкий пик концентрации на определенной глубине с быстрым спадом в соседних слоях. Обычно полное содержание примеси характеризуется долей монослоя этого вещества, а ширина $\delta$-слоя не превышает нескольких нанометров.

Для $\delta$-легирования слоя GaAs марганцем требуется значительное понижение температуры подложки при формировании $\delta$-слоя и последующих слоев полупроводника. Это позволяет подавить диффузию марганца и сохранить дельтообразный вид распределения примеси, однако может приводить к увеличению количества дефектов в полупроводниковых слоях, сформированных после нанесения $\delta$-слоя. Отсюда следует необходимость определения наиболее подходящей температуры эпитаксии, при которой концентрация дефектов в структурах была бы сравнительно низкой, а распределение атомов Mn близко к двумерному.
Концентрация Mn при формировании селективнолегированного слоя GaAs также оказывает значительное влияние на профиль распределения примеси, ее сегрегацию и процесс образования включений второй фазы в структурах, как показано в работе [1] для образцов, изготовленных методом молекулярно-лучевой эпитаксии.

В данной работе изучено влияние параметров импульсного лазерного нанесения - температуры выращивания и содержания примеси в $\delta$-слое - на кристаллические, оптические, электрические и магнитные свойства арсенид-галлиевых структур с одиночным $\delta$-слоем марганца.

\section{2. Методики изготовления и исследования структур}

Образцы были получены сочетанием методов МОСгидридной эпитаксии (МОСГЭ) и импульсного лазерного нанесения (ИЛН) в едином ростовом цикле на подложках $i$-GaAs ориентации (100) [3]. Методом МОСГЭ при температуре $600-650^{\circ} \mathrm{C}$ выращивался буферный слой GaAs толщиной $\sim 0.2-0.3$ мкм. Затем методом ИЛН при температурах $\left(T_{\mathrm{g}}\right)$ от 250 до $450^{\circ} \mathrm{C}$ формировались $\delta$-слой $\mathrm{Mn}$ и покровный слой GaAs толщиной порядка 15-20 нм. В структурах варьировалось содержание марганца $\left(Q_{\mathrm{Mn}}\right)$ в $\delta$-слое от 0.06 до 1.4 монослоя (МС) посредством увеличения времени распыления мишени металлического Mn. Один монослой соответствует слоевой концентрации примеси $6.3 \cdot 10^{14} \mathrm{~cm}^{-2}$. 
Исследования структурных свойств проводились с помощью просвечивающего электронного микроскопа JEM-2100F, работающего при ускоряющем напряжении 200 кВ. Исследования структур методом вторичной ионной масс-спектрометрии (ВИМС) были выполнены на установке TOF.SIMS-5. Послойный анализ проводился с использованием распыляющих пучков ионов $\mathrm{O}_{2}$ или $\mathrm{Cs}$ и анализирующего пучка ионов Вi. Глубина и размеры кратеров травления измерялись с помощью интерференционного микроскопа Talysurf CCI 2000 [4]. Полученные профили распределения элементов были обработаны с использованием нормировки, позволяющей получить концентрационное распределение марганца [5]. Спектры отражения исследуемых структур снимались при комнатной температуре с использованием спектрофотометра Cary 6000i. В качестве эталона использовалось алюминиевое зеркало.

Гальваномагнитные свойства структур изучались в температурном диапазоне от 10 до $300 \mathrm{~K}$ с использованием гелиевого криостата замкнутого цикла Janis CCS-300S/202. Измерение намагниченности производилось при $300 \mathrm{~K}$ с помощью магнитометра переменного градиента магнитного поля.

\section{3. Экспериментальные результаты и обсуждение}

Вначале были проведены исследования по определению оптимальной температуры импульсного лазерного нанесения, поскольку она во многом определяет кристаллическое, оптическое качество структур и диффузионные процессы при $\delta$-легировании Mn слоя GaAs. Для этого была использована серия структур, в которых температура формирования слоев методом ИЛН варьировалась в пределах от 250 до $450^{\circ} \mathrm{C}$, а содержание марганца в $\delta$-слое не превышало $0.2-0.3 \mathrm{MC}$.

Диагностика кристаллического качества низкотемпературных слоев изготовленных образцов была реализована с использованием спектроскопии отражения. Для полупроводника GaAs глубина проникновения излучения кванта с энергией $\sim 3$ эВ составляет порядка 20 нм, что сопоставимо с толщиной покровного слоя GaAs. Очевидно, что преимущественный вклад в отраженный сигнал в области энергий 3-4эВ дает не буферный слой, сформированный МОСГЭ при $600-650^{\circ} \mathrm{C}$, а низкотемпературный слой $\mathrm{GaAs}$, сформированный методом ИЛН поверх $\delta$-слоя $\mathrm{Mn}$. Этот факт позволяет оценить структурное совершенство именно низкотемпературного слоя GaAs.

Полученные спектры отражения в диапазоне энергий кванта от 2 до 4 эВ представлены на рис. 1. На спектрах структур с температурой формирования покровного слоя GaAs 450 и $380^{\circ} \mathrm{C}$ (зависимости 1 и 2) присутствует хорошо разрешаемый дублет пиков с энергиями $E_{1}$ и $E_{1}+\Delta_{1}$, соответствующий переходам в направлении $\Lambda$ зоны Бриллюэна, где зона проводимости и валентная

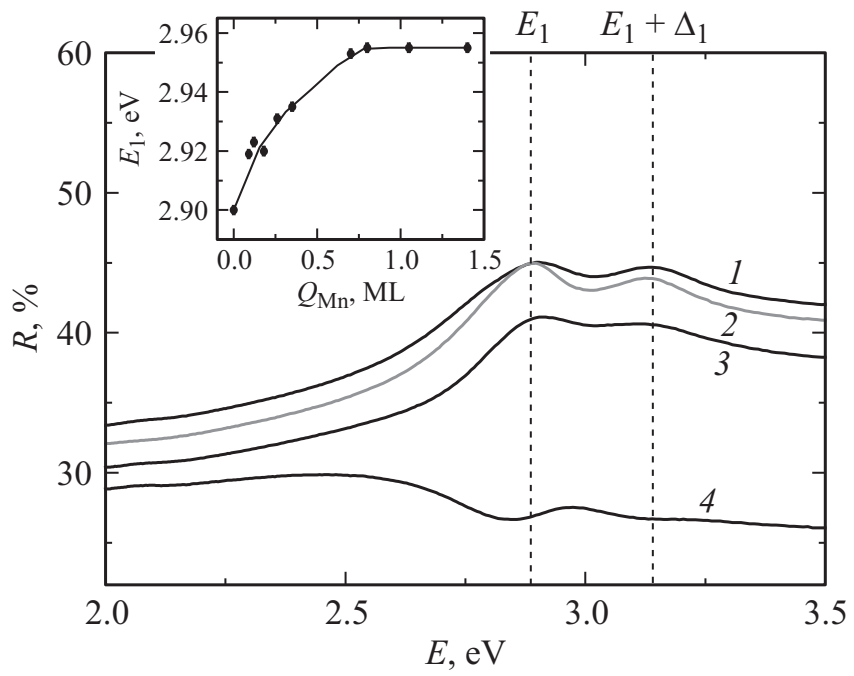

Рис. 1. Спектры отражения структур с $\delta$-слоем марганца $\left(Q_{\mathrm{Mn}}=0.24 \mathrm{MC}\right)$, сформированным при различных температуpax подложки $T_{\mathrm{g}},{ }^{\circ} \mathrm{C}: 1-450,2-380,3-308,4-250$. Пунктирные линии соответствуют положению пиков дуплета для нелегированного GaAs. На вставке приведена зависимость энергии перехода $E_{1}$ от содержания $\mathrm{Mn}$ в $\delta$-слое для образцов c $T_{\mathrm{g}}=400^{\circ} \mathrm{C}$.

зона расположены практически параллельно [6]. Наличие данного дуплета указывает на высокое кристаллическое качество покровного GaAs-слоя [6]. Понижение температуры лазерного нанесения $\mathrm{GaAs}$ до $300^{\circ} \mathrm{C}$ способствует значительному ухудшению структурных свойств покровного слоя. В спектре 3 (рис. 1) пики с характерными для GaAs энергиями $E_{1}$ и $E_{1}+\Delta_{1}$ разрешаются значительно хуже по сравнению со спектрами 1 и 2, и можно полагать, что в данном случае образовалась мозаичная кристаллическая структура. Спектр отражения $4\left(T_{\mathrm{g}}=250^{\circ} \mathrm{C}\right)$ позволяет заключить, что материал покровного слоя является поликристаллическим или аморфным (значения коэффициента отражения снизились существенным образом). Характерный дублет пиков не виден, вместо него в спектре отражения присутствует небольшой провал в области энергий кванта около 2.9 эВ.

По данным высокоразрешающей просвечивающей электронной микроскопии (ПЭМ), слои $\mathrm{GaAs}$, полученные методом ИЛН при температурах $380-450^{\circ} \mathrm{C}$, являются эпитаксиальными. Они имеют высокое кристаллическое качество, сопоставимое со структурным совершенством буферного слоя GaAs, выращенного методом МОСГЭ при $600-650^{\circ} \mathrm{C}$. Исследования в режиме сканирующей ПЭМ (светлопольное изображение) показали наличие контраста в области расположения $\delta$-слоя марганца (рис. 2). Так как атомная масса марганца меньше атомных масс галлия и мышьяка, наблюдаемый контраст нельзя связывать с атомным фактором рассеяния. Можно предположить, что темное изображение слоя марганца появляется вследствие влияния структурного 


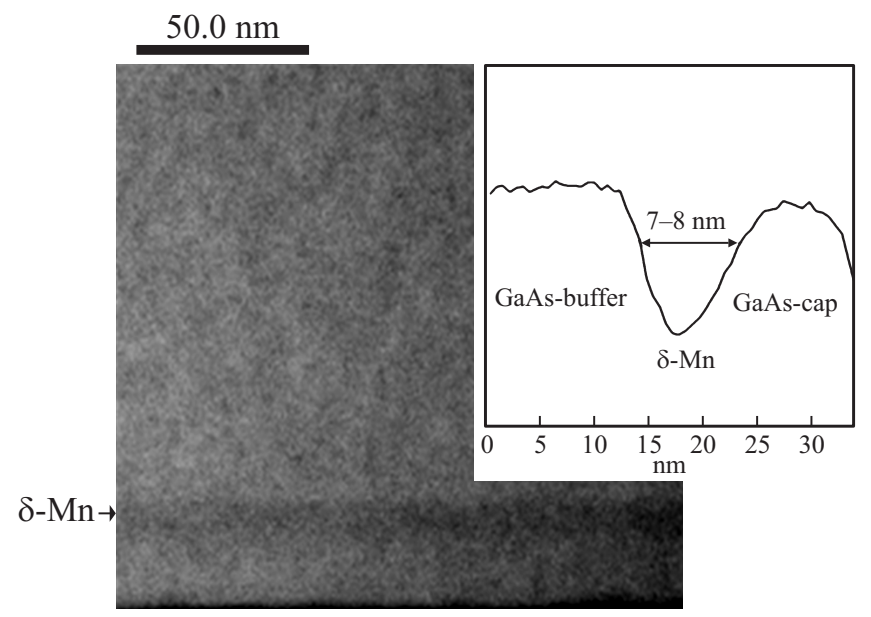

Рис. 2. ПЭМ изображение GaAs-структуры с одиночным $\delta$-слоем $\mathrm{Mn}\left(Q_{\mathrm{Mn}}=0.3-0.35 \mathrm{MC}, T_{\mathrm{g}}=400^{\circ} \mathrm{C}\right)$. На вставке приведено усреднение контраста ПЭМ профиля образца.

фактора рассеяния, который в данном случае может быть обусловлен изменением параметра кристаллической решетки GaAs при внедрении $\mathrm{Mn}$ в количестве нескольких атомных процентов по отношению к галлию (значительно выше предела растворимости). Кроме того, определенная часть марганца может занимать межузельные положения $\left(\mathrm{Mn}_{\mathrm{I}}\right)$, при этом концентрация атомов

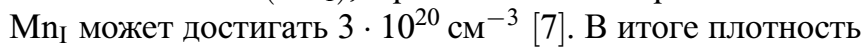
атомов в $\delta$-легированном $\mathrm{Mn}$ слое увеличится, и это также будет давать вклад в структурный фактор рассеяния. Интенсивность изображения $\delta$-слоя можно считать пропорциональной содержанию примеси. Поэтому предполагается, что обработанное с использованием графического пакета (Gatan Digital Micrograph V.2.32) ПЭМизображение позволяет получить достаточно точную информацию о профиле распределения примеси марганца (см. вставку на рис. 2). Полученный усредненный профиль контраста образца с одиночным $\delta$-слоем $\mathrm{Mn}$ $\left(Q_{\mathrm{Mn}}=0.3-0.35 \mathrm{MC}\right)$ можно использовать для оценки ширины легированного марганцем слоя GaAs, которая составляет около 7-8 нм. Этот результат согласуется с данными ВИМС исследований (рис. 3). Следует отметить, что профиль контраста и ВИМС-профиль марганца находятся в хорошем соответствии в приповерхностной области структуры, где наблюдается сегрегация примеси. Представленные концентрационные профили $\mathrm{Mn}$ демонстрируют влияние содержания примеси в $\delta$-слое на преимущественную диффузию атомов к поверхности структуры.

Кроме управления степенью структурного совершенства, температура импульсного лазерного нанесения оказывает также значительное влияние и на электрические свойства $\delta$-легированных Mn структур. Посредством измерения эффекта Холла установлено, что все образцы демонстрируют дырочную проводимость, кроме образца с $T_{\mathrm{g}}=250^{\circ} \mathrm{C}$, для которого наблюдалась слабая электронная проводимость при комнатной температуре. На рис. 4 приведены зависимости слоевого сопротивления образцов от температуры выращивания, измеренные при комнатной температуре и температуре жидкого азота. Видно, что минимум слоевого сопротивления на обеих зависимостях достигается в области $T_{\mathrm{g}}=400^{\circ} \mathrm{C}$. Для данной температуры роста наблюдается максимальная слоевая концентрация носителей заряда $p_{s} \sim 1.4 \cdot 10^{14} \mathrm{~cm}^{-2}$; для сравнения при $T_{\mathrm{g}}=450$ и $350^{\circ} \mathrm{C}$ значение $p_{s}$ на порядок величины ниже $\left(2.7 \cdot 10^{13}\right.$ и $1.1 \cdot 10^{13} \mathrm{~cm}^{-2}$ соответственно). Именно при температурах вблизи $400^{\circ} \mathrm{C}$ процесс ИЛН обеспечивает наиболее высокую электрическую активность атомов $\mathrm{Mn}$ (отношение слоевой концентрации дырок к $Q_{\mathrm{Mn}}$ ). Ее значение составляет 0.1-0.3, что на порядок величины больше, чем для аналогичных образцов, полученных методом молекулярно-лучевой эпитаксии [1]. Кроме того, наблюдение аномального эффекта Холла и отрицательного

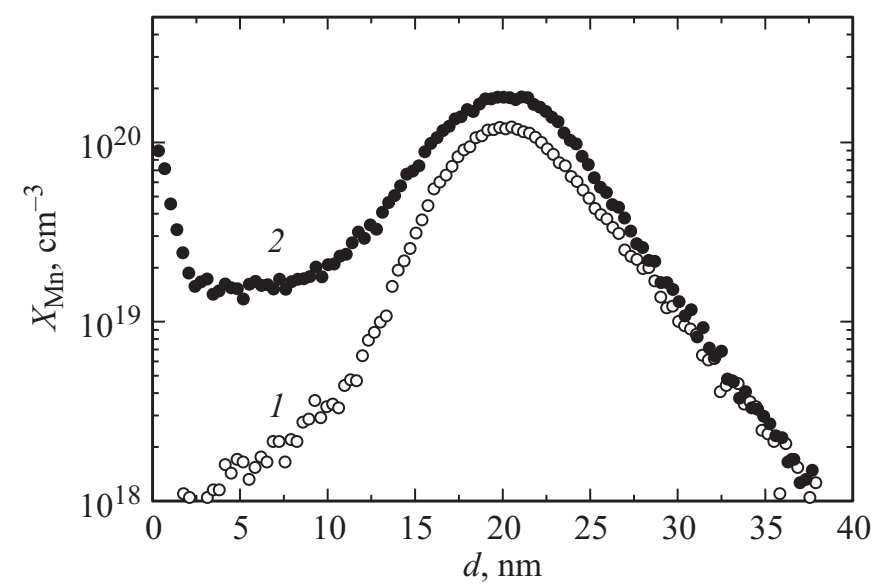

Рис. 3. ВИМС профили концентрационного распределения примеси $\mathrm{Mn}$ по глубине в структурах с одиночным $\delta$-слоем $\left(T_{\mathrm{g}}=400^{\circ} \mathrm{C}\right)$ для значений $Q_{\mathrm{Mn}}$, MC: $1-0.3,2-0.18$.

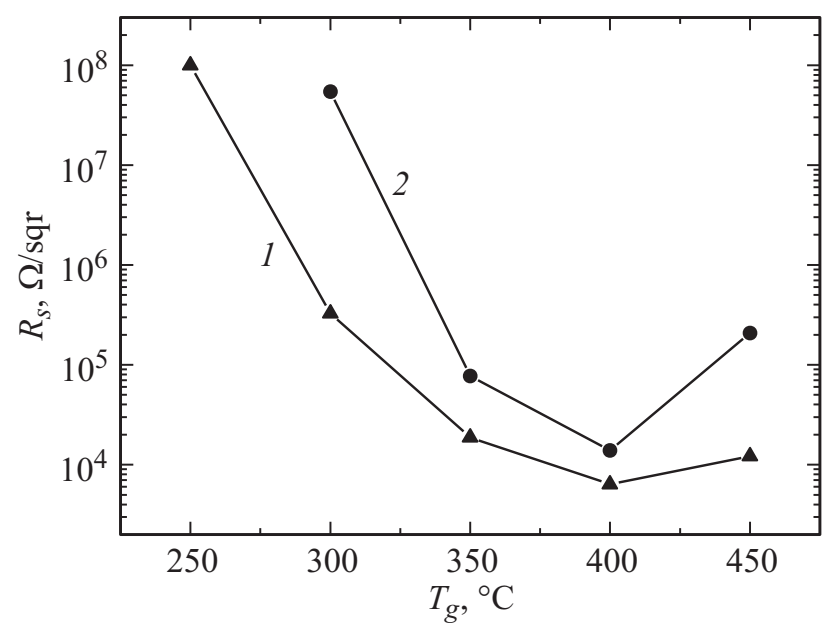

Рис. 4. Зависимости слоевого сопротивления (при 300 (1) и $77 \mathrm{~K}(2))$ GaAs-структур с одиночным $\delta$-слоем $\mathrm{Mn}$ $\left(Q_{\mathrm{Mn}}=0.2 \mathrm{MC}\right)$ от температуры ИЛН. 
магнетосопротивления при низких температурах (от 10 до $35-40 \mathrm{~K}$ ) свидетельствует о ферромагнетизме структур с $T_{\mathrm{g}}=400^{\circ} \mathrm{C}[2]$.

Для проведения исследований по влиянию концентрации примеси в $\delta$-слое на свойства арсенидгаллиевых структур была использована серия образцов с одиночным $\delta$-слоем марганца, сформированным при $T_{\mathrm{g}}=400^{\circ} \mathrm{C}$. Содержание $\mathrm{Mn}$ варьировалось от 0.06 до $1.4 \mathrm{MC}$.

На спектрах отражения изготовленных образцов, за исключением структур с содержанием $\mathrm{Mn}$ в $\delta$-слое $\geq 1 \mathrm{MC}$, также присутствует хорошо разрешаемый дублет пиков $E_{1}$ и $E_{1}+\Delta_{1}$. При увеличении $Q_{\mathrm{Mn}}$ от 0.09 до $0.3 \mathrm{MC}$ наблюдается уменьшение интенсивности пиков дублета и небольшое их уширение. При содержании марганца в $\delta$-слое $\geq 1 \mathrm{MC}$ на спектре разрешается лишь один пик. Наиболее вероятная причина - это появление разупорядочения вследствие введения большого количества примеси в тонкий слой полупроводника. Кроме того, с увеличением $Q_{\text {Мn }}$ в $\delta$-слое происходит смещение пиков дуплета в область больших энергий по отношению к их положению для нелегированного GaAs. Наблюдаемый „синий“ сдвиг наиболее отчетливо проявляется для первого пика дублета, отвечающего переходу $E_{1}$. Зависимость энергии перехода $E_{1}$ от содержания $\mathrm{Mn}$ в $\delta$-слое приведена на вставке к рис. 1 . Для структуры с $Q_{\mathrm{Mn}}=0.09 \mathrm{MC}$ этот сдвиг составляет 20 мэВ и увеличивается до $55 \mathrm{мэB} \mathrm{при} Q_{\mathrm{Mn}}=0.7 \mathrm{MC}$, а далее не изменяется вплоть до $1.4 \mathrm{MC}$. Аналогичный „синий“ сдвиг присутствовал на спектральных зависимостях коэффициента отражения для однородно легированных слоев GaMnAs. Величина сдвига увеличивалась с ростом содержания марганца и достигала 150 мэВ при концентрации $\mathrm{Mn} 6.6 \%$ [8]. Подобное поведение дуплета объясняется $s p-d$-гибридизацией примесной зоны $\mathrm{Mn}$ и валентной зоны GaAs. В нашем случае $\delta$-легированные марганцем слои GaAs можно представить как тонкие ( $<10$ нм) легированные слои GaMnAs, что по аналогии позволяет говорить о наличии $s p-d$-гибридизации.

По данным измерений эффекта Холла, для данной серии образцов были рассчитаны значения эффективной подвижности $\left(\mu_{\text {eff }}\right)$ и слоевой концентрации носителей заряда. Полученные при комнатной температуре зависимости $p_{s}$ и $\mu_{\text {eff }}$ от содержания марганца показаны на рис. 5. Наблюдается рост слоевой концентрации носителей (от $3.7 \cdot 10^{12}$ до $5 \cdot 10^{13} \mathrm{~cm}^{-2}$ ) при увеличении содержания Mn от 0.06 до $\sim 0.3-0.4 \mathrm{MC}$, а затем - выход на насыщение. При этом эффективная подвижность дырок для структур уменьшается от 80 до $20 \mathrm{~cm}^{2} /(\mathrm{B} \cdot \mathrm{c})$. При дальнейшем увеличении содержания марганца до $1.4 \mathrm{MC}$ величина $\mu_{\text {eff }}$ практически не изменяется.

Причиной такого поведения $p_{s}$, по-видимому, является тот факт, что при высокой концентрации $Q_{\mathrm{Mn}}$ атомы $\mathrm{Mn}$ могут занимать межузельные положения, а не только замещать атомы $\mathrm{Ga}$, играя роль акцептора, при этом становясь двойными донорами и приводя тем самым к автокомпенсации [7]. Также возможен переход части

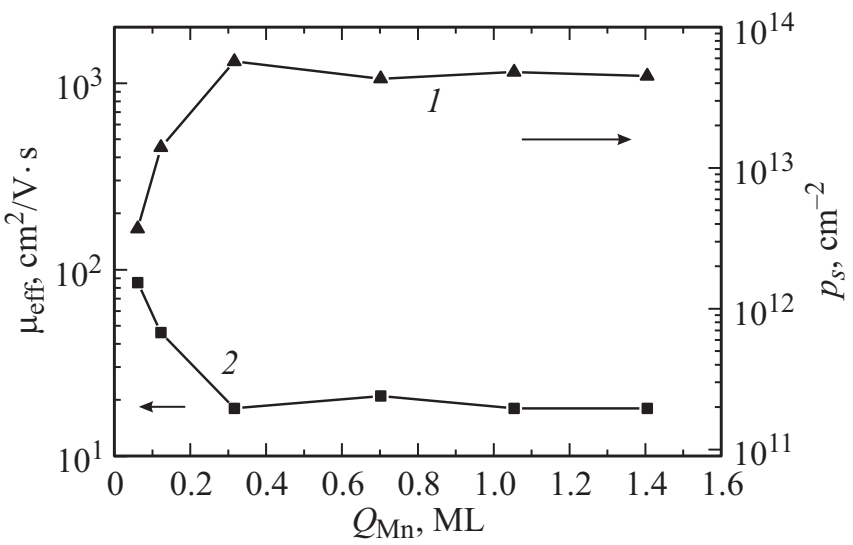

Рис. 5. Зависимости слоевой концентрации $(1)$ и эффективной подвижности (2) носителей заряда от содержания $\mathrm{Mn}$ для GaAs-структур с одиночным $\delta$-слоем $\left(T_{\mathrm{g}}=400^{\circ} \mathrm{C}\right)$ при $300 \mathrm{~K}$.

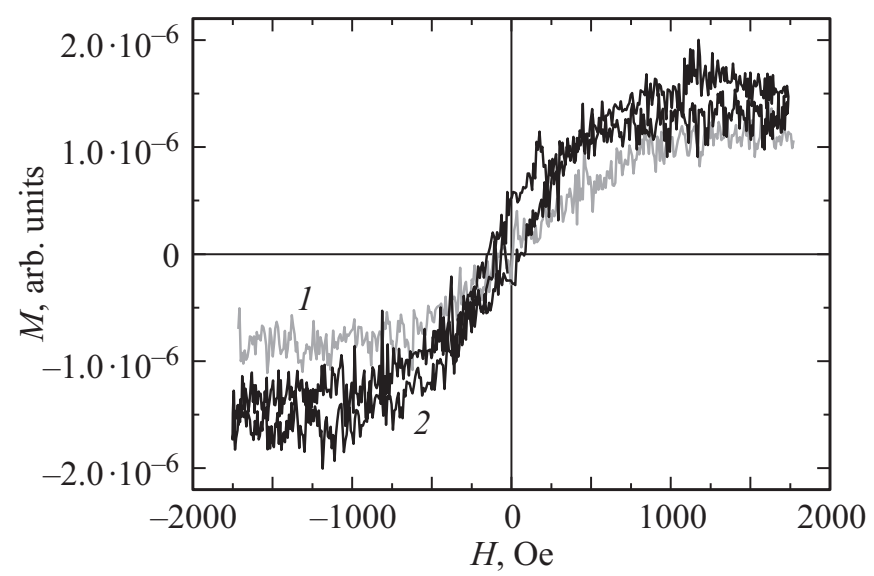

Рис. 6. Магнитополевые зависимости намагниченности структур с одиночным $\delta$-слоем $\mathrm{Mn}\left(T_{\mathrm{g}}=400^{\circ} \mathrm{C}\right)$ при $300 \mathrm{~K}$ для значений $Q_{\mathrm{Mn}}, \mathrm{MC}: 1-1.1,2-1.4$. Магнитное поле приложено в плоскости структуры.

атомов марганца в электрически неактивное состояние с образованием фазы MnAs при $Q_{\mathrm{Mn}}>1 \mathrm{MC}$ [1]. Возможное присутствие кластеров ферромагнитного соединения MnAs (температура Кюри которого составляет $315 \mathrm{~K}$ [9]) в полученных нами структурах с большим содержанием Mn подтверждается исследованием магнитополевых зависимостей намагниченности $M(H)$ при комнатной температуре (рис. 6). Нелинейные зависимости $M(H)$ с петлей гистерезиса были зарегистрированы только для структур с $Q_{\mathrm{Mn}}>1 \mathrm{MC}$.

\section{4. Заключение}

Проведенные исследования позволили определить оптимальные условия формирования импульсным лазерным нанесением селективно-легированных марганцем GaAs-структур: температура подложки около $400^{\circ} \mathrm{C}$ и содержание марганца не более $0.2-0.3 \mathrm{MC}$. По данным 
спектроскопии отражения, высокоразрешающей просвечивающей электронной микроскопии и вторичной ионной масс-спектрометрии, использование указанных параметров выращивания позволяет получать арсенидгаллиевые структуры хорошего кристаллического качества, в которых марганец сосредоточен в тонком (7-8 нм) слое без существенного диффузионного размытия профиля и сегрегации. Такие структуры обладают наибольшей слоевой концентрацией носителей заряда $\left(1.4 \cdot 10^{13}-4 \mathrm{~cm}^{-2}\right)$ и демонстрируют высокую электрическую активность. Кроме того, в этих структурах реализуется ферромагнитное упорядочение при температурах до $30-40 \mathrm{~K}$. Увеличение содержания примеси марганца до одного монослоя и выше приводит к нарушению кристаллического качества таких структур и формированию в них включений полуметаллической фазы (предположительно, кластеров MnAs), которая является ферромагнитной вплоть до комнатной температуры.

Работа выполнена в рамках реализации государственного задания (проект № 8.1751.2017/ПЧ) Министерства образования науки России, при поддержке РФФИ (гранты № 15-02-07824_a, 16-07-01102_а и 17-37-80008_мол_эв_а), стипендии (конкурс СП-2015) и гранта (МК-8221.2016.2) президента Российской Федерации.

\section{Список литературы}

[1] A.M. Nazmul, S. Sugahara, M. Tanaka. J. Cryst. Growth, 251, 303 (2003).

[2] О.В. Вихрова, Ю.А. Данилов, М.В. Дорохин, Б.Н. Звонков, И.Л. Калентьева, А.В. Кудрин. Письма ЖТФ, 35 (14), 8 (2009).

[3] B.N. Zvonkov, O.V. Vikhrova, Yu.A. Danilov, P.B. Demina, M.V. Dorokhin, V.V. Podol'skiǐ, E.S. Demidov, Yu.N. Drozdov, M.V. Sapozhnikov. J. Optic. Techn., 75, 389 (2008).

[4] R.T. Blunt. CS MANTECH Conference, Vancouver, British Columbia, Canada, 59 (2006).

[5] О.В. Вихрова, Ю.А. Данилов, М.Н. Дроздов, Б.Н. Звонков, И.Л. Калентьева. Поверхность. Рентгеновские, синхротронные и нейтронные исследования, 6, 51 (2012).

[6] F. Lukes, S. Gopalan, M. Cardona. Phys. Rev. B, 47 (12), 7071 (1993).

[7] T. Wojtowicz, J.K. Furdyna, X. Liu, K.M. Yu, W. Walukiewicz. Physica E, 25, 171 (2004).

[8] K.S. Burch, J. Stephens, R.K. Kawakami, D.D. Awschalom, D.N. Basov. Phys. Rev. Lett., 70, 205208 (2004).

[9] F. Matsukura, H. Ohno, T. Dietl. Handbook of Magnetic Materials, 14, 1 (2002).

Редактор А.Н. Смирнов

\section{Features of the selective doping of manganese GaAs structures}

\author{
I.L. Kalentyeva' ${ }^{1}$, O.V. Vikhrova', Yu.A. Danilov', \\ B.N. Zvonkov' ${ }^{1}$, A.V. Kudrin ${ }^{1}$, M.V. Dorokhin ${ }^{1}$, \\ D.A. Pavlov' ${ }^{1}$, I.N. Antonov' ${ }^{1}$, M.N. Drozdov', \\ Yu.V. Usov ${ }^{1}$ \\ ${ }^{1}$ Lobachevsky State University of Nizhny Novgorod, \\ 603950 Nizhny Novgorod, Russia \\ ${ }^{2}$ Institute for Physics of Microstructures, \\ Russian Academy of Science, \\ 603950 Nizhny Novgorod, Russia
}

Abstract The influence a number of process parameters (of impurity content in the $\delta$-Mn layer and its formation temperature) on manganese selective doping of gallium arsenide heterostructures produced by a combination of methods MOCVD and pulsed laser deposition was studied. It is found that when growth temperature is of about $400^{\circ} \mathrm{C}$, and the content of $\mathrm{Mn}$ not more than 0.2-0.3 monolayer, structures exhibit the highest electrical activity and possess ferromagnetic properties. The study of reflectance spectroscopy, high-resolution transmission electron microscopy and secondary ion mass spectrometry showed that use of these conditions of pulsed laser deposition allows to obtain the GaAs structures, having a good crystalline quality, and in which manganese is concentrated in a thin $(7-8 \mathrm{~nm})$ layer without substantial spreading and segregation. 